\title{
Retinopathy of prematurity: understanding ischemic retinal vasculopathies at an extreme of life
}

\author{
Przemyslaw Sapieha, ${ }^{1,2}$ Jean-Sebastien Joyal, ${ }^{3}$ José Carlos Rivera, ${ }^{3}$ Elsa Kermorvant-Duchemin, ${ }^{4}$ \\ Florian Sennlaub, ${ }^{4}$ Pierre Hardy, ${ }^{3}$ Pierre Lachapelle, ${ }^{5}$ and Sylvain Chemtob ${ }^{2,3}$

\begin{abstract}
1Department of Ophthalmology, Children's Hospital Boston, Harvard Medical School, Boston, Massachusetts, USA. 2Department of Ophthalmology, Maisonneuve-Rosemont Hospital Research Center, University of Montreal, Montreal, Quebec, Canada. ${ }^{3}$ Research Center of Centre Hospitalier Universitaire Sainte-Justine, Department of Pediatrics, Ophthalmology and Pharmacology, Montreal, Quebec, Canada. ${ }^{4}$ INSERM UMRS872, Paris, France. ${ }^{5}$ Department of Ophthalmology, Montreal Children's Hospital, Montreal, Quebec, Canada.
\end{abstract}

\begin{abstract}
Retinopathy of prematurity (ROP) is a major complication of preterm birth. It encompasses a spectrum of pathologies that affect vision, from mild disease that resolves spontaneously to severe disease that causes retinal detachment and subsequent blindness. The pathologies are characterized by an arrest in normal retinal vascular development associated with microvascular degeneration. The resulting ischemia and retinal hypoxia lead to excessive abnormal compensatory blood vessel growth. However, this neovascularization can lead to fibrous scar formation and culminate in retinal detachment. Present therapeutic modalities to limit the adverse consequences of aberrant neovascularization are invasive and/or tissue-destructive. In this Review, we discuss current concepts on retinal microvascular degeneration, neovascularization, and available treatments, as well as present future perspectives toward more profound elucidation of the pathogenesis of ROP.
\end{abstract}

Retinopathy of prematurity (ROP) is the major ocular disorder of the neonate $(1,2)$ and the dominant cause of severe visual impairment in childhood in North America and Europe. ROP is associated with significant sequelae, the most serious being retinal detachment, which results in blindness. However, even milder forms of ROP increase the incidence of pathologies that negatively impact visual acuity, for example, ametropias, refractive errors that reduce visual acuity; strabismus, a condition in which the eyes are not properly aligned, preventing proper binocular vision and adversely affecting depth perception; and disorders of color discrimination (3-6). ROP proceeds following an initial phase of degeneration of the retinal microvasculature (vasoobliteration) $(7,8)$ (Figure 1 ) that is associated with cessation of progression of vascular growth toward the retinal periphery. In the subsequent phase of the disease, the ensuing retinal ischemia predisposes to abnormal compensatory neovascularization $(9,10)$. Of the various factors that have been associated with the development of ROP, low birth weight, low gestational age, supplemental oxygen therapy, and its associated relative hyperoxia dominate.

The development of the human retinal vasculature commences at approximately the 16 th week of gestation and concludes at term (i.e., the 40th week of gestation) (11). Hence, when an infant is born prematurely, its retinal blood supply is incomplete and highly vulnerable to decay. This immaturity in vascular development predisposes the retina to complications. Major advances have been made over the past 30 years in identifying mechanisms implicated in the genesis of ROP. Comprehension of mechanisms underlying this disorder has, in turn, enhanced understanding of the pathogenesis of ischemic retinal vasculopathies in the adult, for example, diabetic retinopathy (a complication of diabetes mellitus) and neovascular forms of age-related macular degeneration (the major cause of visual impairment in adults over 50 years of age).

Conflict of interest: The authors have declared that no conflict of interest exists. Citation for this article: J Clin Invest. 2010;120(9):3022-3032. doi:10.1172/JCI42142.
The oxygen-induced retinopathy (OIR) model of ischemic retinopathy $(12,13)$, which adequately reproduces the vasoobliterative and neovascularization phases of ROP and accurately assesses treatment outcome (14), has been a valuable tool to researchers studying ischemic retinopathies, providing substantial insight into these conditions. The OIR model has largely been utilized in rodents because development of the retinal vasculature in these animals occurs mainly after birth, allowing retinal angiogenesis to be studied under both physiologic and pathologic conditions. Understanding both the mechanisms of normal retinal vascular development and the pathophysiological processes leading to primary vascular loss is the key to developing new therapeutic approaches to prevent the sight-threatening neovascularization associated with ROP and ischemic retinal retinopathies in the adult.

In this Review, we address various aspects of ROP pathogenesis, including mechanisms involved in the control of ocular circulation, vasoobliteration, neovascularization, and therapeutic approaches, and outline future perspectives. Although the field of ROP is dynamically expanding into novel areas of research, here we explain key concepts and concentrate on the most widely accepted theories.

\section{Regulation of ocular blood flow}

Relative excess oxygen supply to the premature infant is one of the most important factors involved in the genesis of ROP $(15,16)$. Accordingly, limiting hemoglobin saturation with oxygen by reducing oxygen supplementation has been repeatedly shown to be effective in diminishing the rate of ROP (17-19). To understand the effects of oxygen in the genesis of ROP, it is first important to consider how blood supply to the inner retina is governed. The mechanisms that modulate ocular circulation (as elsewhere in the body) are regulated by a complex interplay of systemic factors (including circulating hormones and autonomic innervation) that affect total cardiac output and factors that regulate flow locally (i.e., variations in perfusion pressure, 


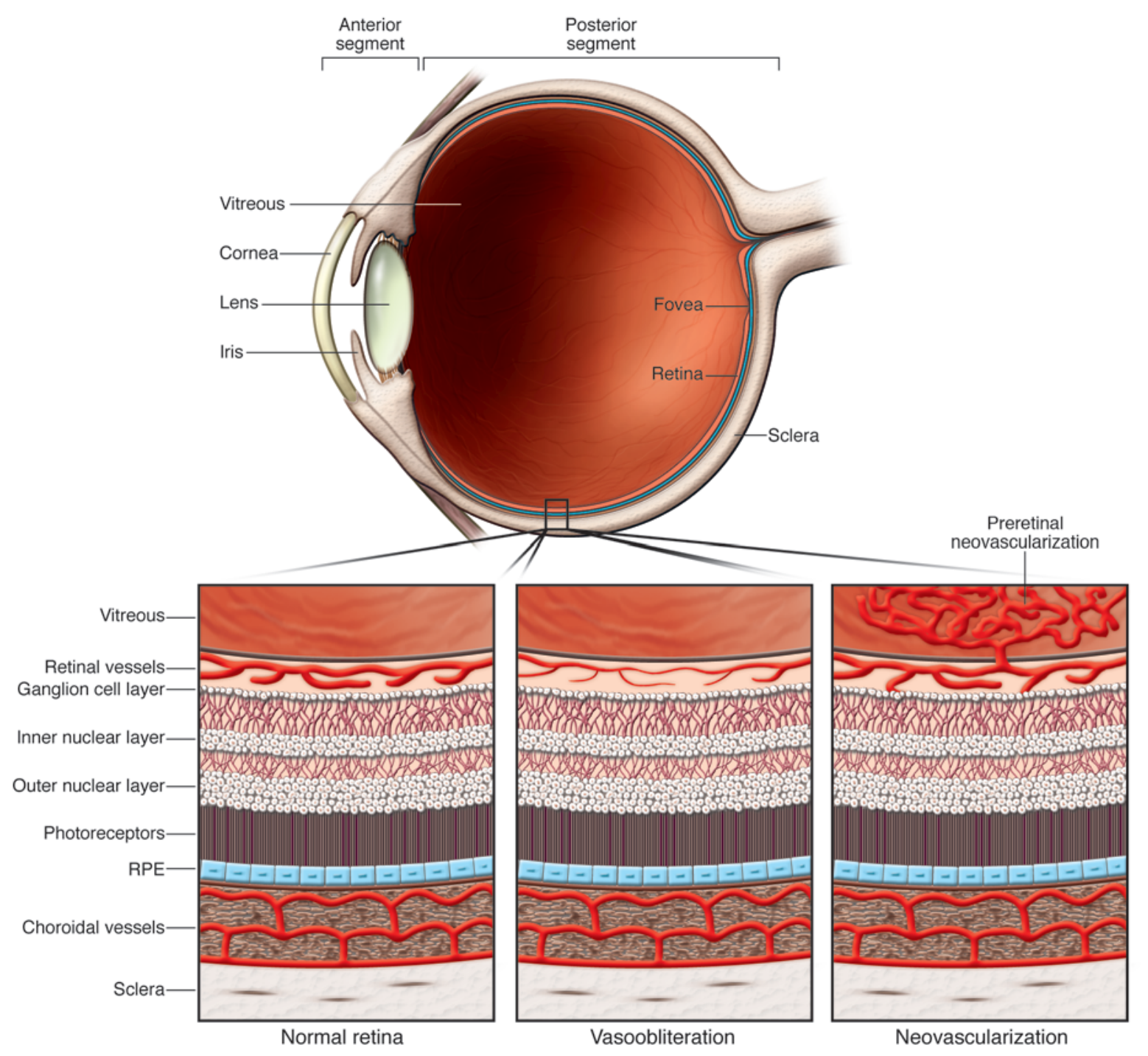

Figure 1

Overview of the pathogenesis of ROP. Schematic depiction of the neural retina and the vascular beds that perfuse it. Retinal vessels (which form preretinal vascular tufts in ROP) are present adjacent to the retinal ganglion cell layer next to the vitreous body. As ROP progresses, there is an initial phase of vascular degeneration (vasoobliteration), followed by a secondary phase of compensatory (but pathologic) angiogenesis toward the vitreous of the retina (preretinal neovascularization). The choroidal vascular plexus, which supplies the outer retina and is affected in age-related macular degeneration, is present behind the photoreceptors at the back of the eye. RPE, retinal pigment epithelium.

$\mathrm{pH}$, partial arterial pressure of oxygen $\left[\mathrm{PaO}_{2}\right]$, and partial arterial pressure of carbon dioxide $\left.\left[\mathrm{PaCO}_{2}\right]\right)$. These factors act in concert to ensure adequate blood supply to meet tissue demand. The retina is predominantly influenced by local factors, as it lacks autonomic vascular innervation (20-22).

The capacity to keep blood flow constant over a range of perfusion pressures and oxygen tensions and to adjust blood flow to meet metabolic demand is termed autoregulation (23). In the adult, retinal blood flow (RBF) is maintained constant over a wide range of perfusion pressures, whereas in the newborn, $\mathrm{RBF}$ is autoregulated over a much narrower range (24-29); moreover, preterm infants who suffer complications of prematurity exhibit total absence of autoregulation of neural blood flow (30-32). Similarly, blood flow to the choroid $(\mathrm{ChBF})$ - the vascular layer that is the major supplier of oxygen to the outer retina and is incompletely vascularized in the immature newborn - is also autoregulated in the adult over a wide range of perfusion pressures, while in the newborn, ChBF autoregulation is essentially absent (25-27,33-36). Autoregulation of ocular blood flow also responds to changes in blood oxygen tension.

In hyperoxia, such as might occur during oxygen supplementation protocols (mechanical ventilation) administered to premature infants to overcome respiratory insufficiency, the retinal vasculature constricts comparably in the newborn and adult $(9,25$, $34,35,37,38)$. However, compared with those in the adult, vessels of the choroid in the newborn do not constrict in hyperoxia. Consequently, during an acute rise in oxygen tension or perfusion pressure, both the RBF and ChBF of the newborn cannot be maintained constant, resulting in an exaggerated delivery of potentially toxic oxygen to the retina (Figure 2$)(25,27,38-41)$. This relative inability of the neonate to control oxygen delivery to the retina is largely due 


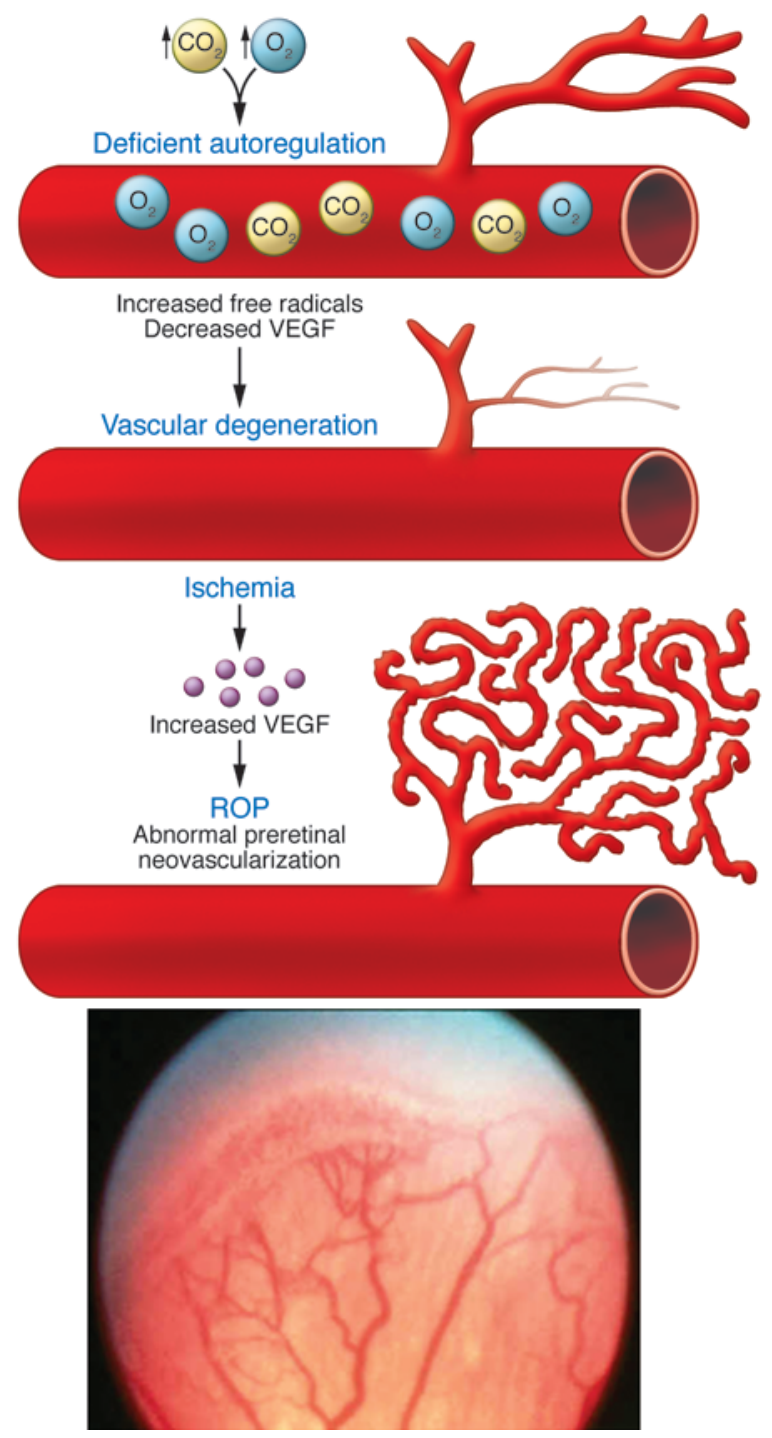

to high perinatal levels of prostaglandins (such as $\mathrm{PGD}_{2}$ and $\mathrm{PGE}_{2}$ ) and NO that profoundly influence vasomotor tone and override the autoregulatory response $(27,38-40,42)$ (Figure 3).

Another factor significantly contributing to the disruption of regulation of RBF and ChBF in infants born prematurely is the rise in carbon dioxide tension (hypercapnia) in conservatively mechanically ventilated and lung-damaged premature infants. Both acute and sustained hypercapnia markedly increase RBF and ChBF in infants born prematurely. The acute rise in ocular blood flow in response to hypercapnia is largely $\mathrm{PGE}_{2}$ dependent. During sustained hypercapnia, this increase in $\mathrm{PGE}_{2}$ induces expression of eNOS, which releases $\mathrm{NO}$ and in turn mediates the delayed carbon dioxide-induced rise in ocular hemodynamics (Figures 2 and 3 ) and further curtails ocular blood flow autoregulation (43). This marked induction in ocular hyperemia is clinically relevant, since hypercapnia is associated with ROP in humans and experimental animals (17).

\section{Vasoobliteration}

Oxygen-dependent factors: oxidative and nitrative stress and their downstream effects. The exaggerated retinal oxygenation secondary to oxygen supplementation, along with the sudden transition from

\section{Figure 2}

Deficient autoregulation in the premature retina. Deficient autoregulation of ocular blood flow in the newborn fails to limit retinal oxygenation during hyperoxia. This results in excess delivery of oxygen to tissues. High carbon dioxide tension increases ocular blood flow and further curtails its autoregulation. Increased retinal oxygenation augments free radical generation and suppresses VEGF expression in the newborn. This leads to arrest in vascular development and microvascular degeneration. The ensuing ischemia triggers the aberrant neovascularization seen in ROP.

low intrauterine to higher extrauterine oxygen tension, results in exposure of immature tissues to a relative excess of oxygen. This provokes endothelial cell death and thus obliteration of retinal vessels, because infants born prematurely are prone to oxidant injury. The neonate retina (and the adult retina) is rich in mitochondria and maintains a high rate of oxidative metabolism readily overwhelmed in this abnormal developmental context (44). The incomplete reduction of oxygen, largely by complex III of oxidative phosphorylation, leads to the generation of ROS (45). In addition, the retina contains numerous molecular photosensitizers that generate free radicals upon excitation (46-48). In contrast to adults, there is more free iron in the neural tissue of newborns to catalyze oxidizing reactions $(49,50)$. Finally, this ability of the retina to generate excessive ROS is not counterbalanced by antioxidants, which are deficient in the immature subject relative to the adult, since the low oxygen-exposed fetus has modest needs for antioxidants in utero $(51,52)$.

Necessary intermediates of constitutive biochemical reactions also generate ROS. Endothelial cell enzymes and transporters, including xanthine oxidase, NADPH oxidase, COX, NOS, and to a lesser extent those involved in lipoxygenase pathways, contribute to the generation of free radicals. Interestingly, COX and NOS activities are high in the neonatal period and contribute to peroxidation in ocular tissues, especially in premature subjects with reduced antioxidant defenses and subjected to exaggerated oxygen tension secondary to mechanical ventilation. During oxidative stress, the COX pathway is an important producer of free radicals, amplified by ROS due to a positive feedback loop (53). Increased COX activity produces more prostaglandins (mostly $\mathrm{PGD}_{2}$ and $\mathrm{PGE}_{2}$ ), themselves upregulating eNOS and NO production to further increase ocular blood flow and oxidant stress to the immature retina. Furthermore, ROS can react with NO to generate highly reactive nitrogen species (RNS), including peroxynitrite, nitrogen dioxide, and dinitrogen trioxide (54). The deleterious effects of these RNSs on cell function are generally referred to as nitrative stress (55) and result in retinal microvascular degeneration $(56,57)$. In line with these findings, endothelial NOS was shown to contribute to retinal vascular degeneration in a mouse model of ROP and increase the ensuing pathologic neovascularization (58). Similarly, inducible NOS (which is upregulated in hypoxia) inhibits physiologic retinal revascularization subsequent to vasoobliteration and encourages preretinal neovascularization (59).

Lipid peroxidation of cell membranes secondary to inadequate oxygen tension is pivotal to the pathogenesis of ROP and, together with nitrative stress, among the most toxic consequences of increased ROS. Polyunsaturated fatty acids (PUFAs) of membrane phospholipids are common targets for peroxidation, resulting in loss of cell membrane function and structural integrity $(60,61)$. For reasons that remain ill defined, retinal endothelial cells are 


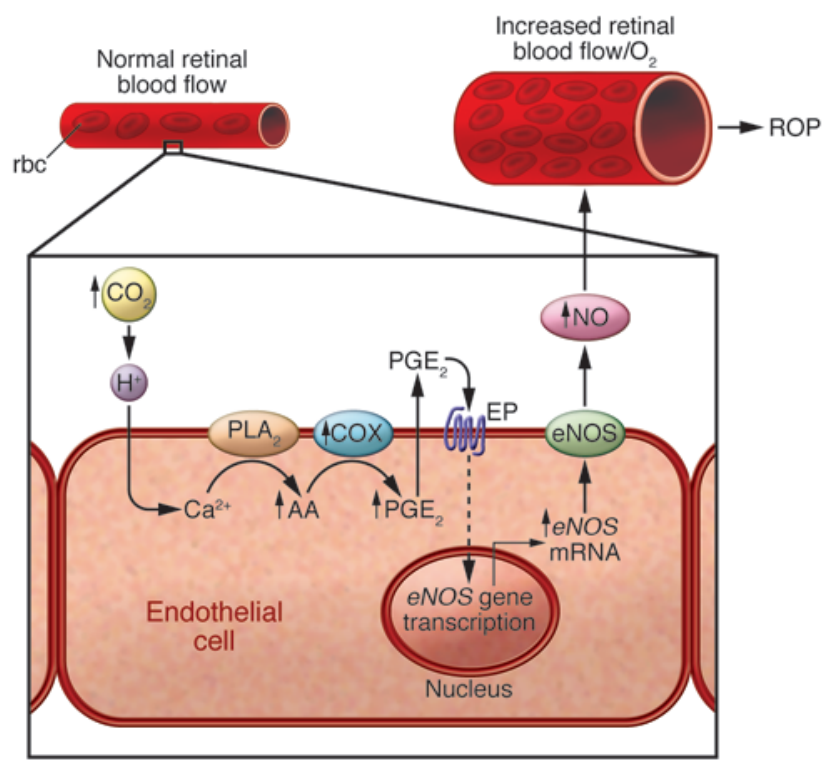

Figure 3

The effects of hypercapnia on RBF. Sustained hypercapnia evokes a marked increase in RBF. This effect is sequentially mediated by calcium entry into endothelial cells, inducing increased $\mathrm{PGE}_{2}$ production and in turn eNOS-derived NO formation.

particularly vulnerable to peroxidation-induced injury, whereas pericytes, smooth muscle cells, and perivascular astrocytes are relatively resistant (62-64). The retina is highly susceptible to lipid peroxidation, being composed of lipids with elevated levels of PUFAs such as docosahexaenoic acid (DHA), cis-arachidonic acid (AA), and choline phosphoglyceride.

Prostanoids are synthesized from AA by the sequential action of phospholipase $\mathrm{A}_{2}\left(\mathrm{PLA}_{2}\right)$ and COX triggered by oxidant stress and peroxidation $(27,39,65,66)$. The accumulation of peroxides eventually favors thromboxane $\left(\mathrm{TXA}_{2}\right)$ production over that of prostaglandins $(39,53)$. In contrast to $\mathrm{TXA}_{2}$ synthase, prostaglandin synthases function best under reducing conditions (which are required by the cofactors glutathione and NADH). $\mathrm{TXA}_{2}$ is a potent vasoconstrictor as well as a cytotoxic agent in microvessels (67). Consistent with these events having a role in ROP, inhibitors of COX (indomethacin) and $\mathrm{TXA}_{2}$ synthase (CGS-12970) selectively curtail oxygen-induced retinal vasoobliteration in mice (67). In contrast to prostaglandins produced by COX, isoprostanes are formed non-enzymatically in situ from the peroxidation of AA and then released by phospholipases; they exceed the production of prostaglandins under oxidizing conditions $(27,53,65,66)$. Isoprostanes may contribute to microvascular injury in ROP, as they are indirectly cytotoxic, since they trigger the production of $\mathrm{TXA}_{2}$ (68-70) (Figure 4).

Nitrative stress results in cis- to trans-isomerization of AA (TAA), and this was recently shown to contribute to retinal vascular degeneration in a mouse model of ROP (71). This reaction yields four stable TAA monoisomers (72) (two of them being endogenous and not found in diet; ref. 73). Circulating levels of plasma TAA (74) are increased in oxygen-induced microvascular degeneration (75) and are known to be associated with induction of nitrative stress $(76,77)$; more specifically, TAA formation is abrogated in mice treated with NOS inhibitors and in mice deficient in eNOS (75) (Figure 4). TAA also exerts endothelial cytotoxicity by inducing formation of the antiangiogenic and proapoptotic thrombospondin-1 (TSP-1) (75). Hence, trans-fats are not only generated during industrial processing of lipids but also formed in vivo and contribute to the microvascular degeneration observed in ischemic retinopathies.

Other lipids generated during peroxidation are important proinflammatory mediators; these include lysophosphatidic acid (LPA) and platelet-activated factor (PAF). Choline phosphoglycerides are the precursors of PAF. Constitutive levels of PAF are maintained by the de novo pathway to ensure normal housekeeping cellular function. Otherwise, PAF is abundantly generated under oxidative stress by the remodeling pathway and calcium-dependant activation of cytosolic PLA $\mathrm{PA}_{2}$. In ROP, AAs are cleaved off from membrane phospholipids (by cPLA $_{2}$ to yield lysophospholipids, which in turn can be acetylated and converted to PAF (78). Both vasomotor and cytotoxic effects of PAF in the premature infant are mediated to a large extent by $\mathrm{TXA}_{2}(79,80)$. Thus, PAF, which is generated concomitantly with $\mathrm{TXA}_{2}$ during oxidant stress and amplifies formation of $\mathrm{TXA}_{2}$, contributes to retinal vasoobliteration in ischemic retinopathies (Figure 4). Likewise, LPA is also released from lysophosphatidylcholine by the action of lysophospholipase $\mathrm{D}(81)$ and can partake in retinal inflammation leading to microvascular cytotoxicity (82).

Oxygen-dependent factors: suppression of oxygen-regulated growth factors. The underlying function of a healthy vascular bed is the proper delivery of oxygen and nutrients to the tissue in order to guarantee adequate levels of energy production. This fundamental task ensures cellular respiration and consequently systemic survival. Organisms have therefore developed a series of effective metabolically driven, oxygen-sensing mechanisms to reinstate local capillary supply when perfusion is disrupted (83-85). In a mature organism, tissue oxygenation is tightly regulated to ensure sufficient supply without excess (described above). Conversely, the immature retina of neonates poorly regulates oxygen delivery to its tissue, leading to excess oxygenation when ventilated at high oxygen tension in oxygen supplementation protocols.

Beyond direct oxidative damage to the endothelium, excess retinal oxygenation plays an important role in the pathogenesis of ROP by suppressing key oxygen-regulated growth and survival factors. This occurs at the transcriptional level via the oxygen-sensing transcription factor HIF (86), which is composed of two distinct $\alpha$-and $\beta$-subunits that must heterodimerize in order to be active (87). HIF1A is constitutively transcribed but has an ephemeral half-life of only 5 minutes under normoxic conditions (88). The swift turnover is catalyzed by proline hydroxylation of its oxygendependent degradation domain by HIF-1 $\alpha$ prolyl hydroxylases (PHDs). The ultimate result is polyubiquitination and targeting for proteasomal degradation. Conversely, in hypoxic conditions, proline hydroxylation hardly occurs and HIF-1 $\alpha$ is stabilized. It is then free to translocate to the nucleus, where it dimerizes with HIF-1 $\beta$ and initiates transcription of target genes that have a hypoxia-response element (HRE) (89).

HIF- $1 \alpha$ is important for both the vasoobliterative phase of ROP (where the production of key growth factors is suppressed) and the neovascularization phase (where retinal hypoxia provokes the excess production of angiogenic factors). HIF drives the transcription of a cluster of genes (presently over 60 have been described) that encode proteins that promote the adjustment to a hypoxic state $(90,91)$ and help to reinstate local tissue perfusion. These genes include 


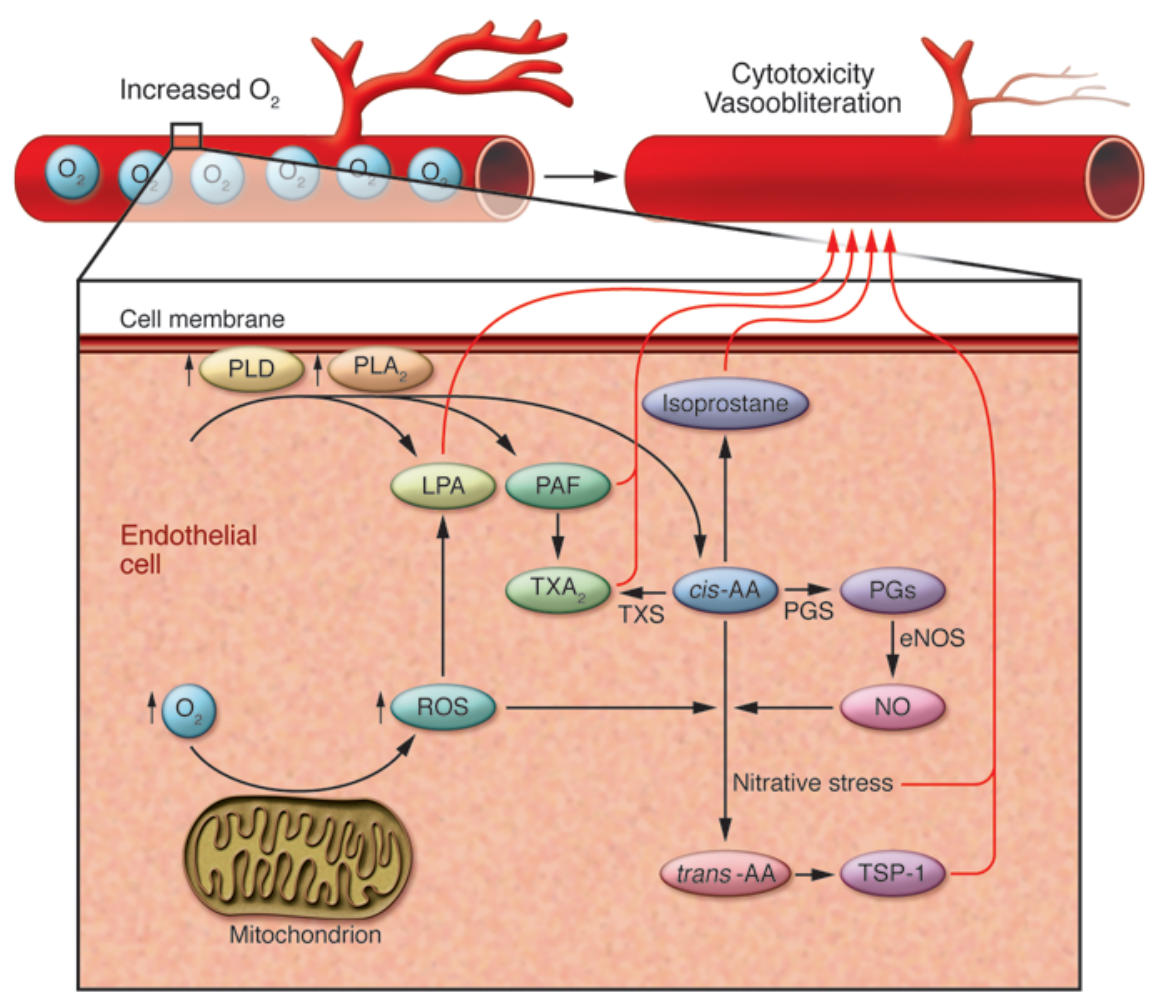

\section{Figure 4}

The effects of oxidant stress on premature retinal vasculature. The premature retina is relatively deficient in antioxidants. Consequently, oxidant stress is more likely to induce peroxidation and nitration that is cytotoxic to retinal microvasculature. Downstream mediators of peroxidation, notably the phospholipids PAF and LPA, the non-enzymatically derived prostanoids, isoprostanes, and nitration products (of particular relevance here are the trans-AAs) are all cytotoxic to retinovascular endothelium, causing vasoobliteration. PGS, PG synthase; TXS, thromboxane synthase. those that encode enzymes involved in energy production, such as glucose transporter-1 (GLUT-1) and the key glycolytic enzyme aldolase A (92). Moreover, HIF promotes production of angiogenic factors such as VEGF (93) and erythropoietin (Epo) (94) that will participate in establishing retinal vascular networks. Once the tissue is revascularized, the hypoxic stimulus is alleviated and HIF degraded. When oxygen levels are exaggerated, as occurs during the early phase of ROP, HIF is preemptively suppressed and its target genes not transcribed. In this context, oxygen-regulated growth factors such as VEGF and Epo are suppressed; VEGF suppression contributes to the arrest in vascular development and compromised endothelial survival (95) seen in the hyperoxic phase of $\operatorname{OIR}(96,97)$. The requirement for VEGF in normal physiological retinal vascular growth is well established. As the neuronal retina differentiates and metabolic activity increases, vascular growth is initiated in response to waves of tissue hypoxia, largely via the production of VEGF by retinal ganglion cells (83) and astrocytes (98) For its part, Epo is well described as a renal-derived hormone produced in response to hypoxia or anemia to stimulate erythrocyte production. Like VEGF, Epo levels drop substantially during hyperoxia (99). Its role in the pathogenesis of ROP has been elegantly addressed in the work of Chen et al. (99), in which this cytoprotective agent was shown to preserve (via activation of pro-survival NF-кB) the retinal vascular bed and protect retinal neurons against apoptosis when administered in early phases of retinopathy. Interestingly, systemic delivery of Epo can also stimulate mobilization of $\mathrm{CD} 34^{+}$endothelial progenitor cells and colony-stimulating factor 1 receptor $^{+}\left(\mathrm{Csf}-1 \mathrm{R}^{+}\right)$microglia to the retina. Given that both of these cell populations are important in the repair of injured retinal vasculature, it is likely that in addition to promoting cell survival via activation of its receptor, Epo can also promote retinal vascular repair by recruiting bone marrow-derived proangiogenic cells to the retina.
Oxygen-independent factors. In light of the major role of high levels of oxygen and their resulting effects in the genesis of ROP, oxygenation protocols limiting hemoglobin saturation with oxygen have been adapted to the clinic and shown to reduce the incidence of ROP $(18,19,100)$. However, these approaches have not eliminated ROP in the industrialized world, suggesting a role for oxygen-independent factors in the development of ROP. Of all these contributors, premature birth remains the greatest risk for ROP (101), which suggests that perhaps certain factors present in utero required for normal fetal development may be lacking in infants born prematurely. This hypothesis was explored in detail in the seminal works of Lois Smith on IGF-1, a polypeptide protein hormone whose fetal plasma levels rise with gestational age and considerably increase during the third trimester of pregnancy but are considerably lower in premature infants born early during the last trimester (102-105). Evidence implicating a paucity of IGF-1 in ROP was demonstrated in IGF-1-deficient mice, in which retinal vessel growth was retarded, akin to patterns noted in premature babies with ROP (102). Similarly, in human subjects, low IGF-1 serum levels directly correlate with the severity of ROP and interestingly may also account for abnormal brain development (106).

In neonatal mice with decreased IGF-1, it was observed that VEGF levels remain elevated in OIR, yet these animals are resistant to hypoxia-induced retinopathy (105). These findings point to a mechanism of action whereby IGF-1 would not directly modulate VEGF levels. In fact, IGF-1 potentiates the maximal VEGF-induced activation of Akt in endothelial cells and therefore modulates vessel survival (104), an essential event in preventing the first phase of ROP. IGF-1 also seems to be permissive for VEGF-induced activation of $\mathrm{p} 44 / 42 \mathrm{MAPK}$, which is essential for endothelial cell proliferation and thus the neovascularization observed in the second phase of ROP (105). In this regard, IGF-1 acts as a permissive factor for VEGF-dependent endothelial growth and survival. 
The action of IGF-1 is dependent upon the concentration of IGF-binding proteins (IGFBPs), which prolong its circulating half-life and thus augment tissue delivery (107). Once in the tissue, IGFBPs can either potentiate IGF-1 signaling by releasing it in the proximity of its receptors or conversely hinder signaling by sequestering it. In infants born prematurely at 30-35 weeks gestation, levels of the most abundant IGFBP, IGFBP3, were found to be markedly diminished in infants with ROP as compared with those without (103). And in mice subjected to OIR, augmentation of IGFBP3 levels increased vessel survival (in an IGF-1independent manner) and consequently reduced the severity of the retinal vasculopathy (103).

In line with the obligate presence of adequate levels of IGF-1 (and/or IGFBP3) for normal retinal vascular development, clinical trials are being undertaken to supplement IGF-1 and IGFBP3 to in utero levels in infants born prematurely (108). Moreover, based on the observations presented above, the question of whether poor weight gain is a contributing risk factor for ROP in infants born prematurely has been raised. In this context, it was recently found that inadequate weight gain during the first few weeks of postnatal life is associated with more severe ROP (109). An algorithm based on weight gain and IGF-1 levels was developed to predict the risk of ROP and termed WINROP. Using serial weight and IGF-1 measurements in a cohort of 50 premature babies, WINROP predicted all infants who later developed ROP by a mean age of 10 weeks (109). Furthermore, measurements of weight gain (and exclusion of IGF-1) was sufficient to demonstrate in a cohort of 351 patients that insufficient weight gain could predict all infants that required treatment and $75 \%$ of babies who did not develop ROP (110). These findings emphasize the importance of adequate metabolic supply to the developing fetus and its role in proper retinal vascular development.

\section{Neovascular proliferation}

In an attempt to reinstate adequate levels of oxygen and nutrients to the vasoobliterated retina, the hypoxic/ischemic tissue orchestrates a vasoreparative growth program triggered by the now metabolically deficient situation in the retina. In contrast to normal developmental growth, this neovascularization is excessive, disorganized, and misdirected toward the vitreous, which is devoid of vessels under physiological conditions (Figure 1). This destructive secondary angiogenesis is driven by an exaggeration of many of the same hypoxia-driven stimuli that coordinate physiological vessel growth in the embryonic retina. Therefore, valuable insight into the molecular mechanisms governing the pathogenesis of proliferative ROP can be gained through a better understanding of retinal vascular development.

Physiological retinal vascular development. Mammalian retinas of various species, including humans and mice, form vascular networks with highly reproducible growth patterns, suggesting a tightly regulated and carefully guided growth process that is the sum of responses to pro- and antiangiogenic factors (111). Retinal vascular growth must be restricted to the retina, as misdirected vessels to the adjacent vitreous body would obstruct incoming light. Several mechanisms are in place to ensure this directed growth, such as formation of junctions with the astrocytic bed (112) and graded production of VEGF by neuroglia (113) and retinal ganglion cells (83) on the retinal surface.

The superficial retinal vascular plexus (which is affected in ROP) forms by angiogenesis (Figure 1) (114-117). As indicated above, regions of the tissue that are poorly supplied with oxy- gen and nutrients prompt formation of neovessel sprouts from the walls of preexisting blood vessels in response to oxygen tension-sensitive growth factors such as VEGF and Epo $(95,99)$ and other oxygen-independent factors such angiopoietins/Tie2 (118) and IGF-1 (105). Once the new vessel forms, its growth is steered by specialized endothelial tip cells (119) that probe and sense chemoattractive and repulsive environmental cues at the vascular front. Tip cells respond to VEGF by forming motile filopodia enriched in VEGFR2 and rich in guidance receptors such as neuropilin-1, Unc5b, and Eph (120-122) that respond to directional cues (119). Stalk cells (the endothelial cells that follow the tip cell) responding to VEGF with proliferation, follow to form the nascent vessel with a lumen $(119,123)$. The final maturation of vessels requires pruning of excess vasculature (124) and recruitment of mural cells (pericytes in medium-sized vessels and smooth muscle cells in large vessels) (125).

Pathological neovascularization. Throughout the proliferative phase of ROP, the proangiogenic response originates from neurons (83) and supporting astrocytes (98). These cell populations are severely metabolically deprived following the vasoobliteration during the first phase of ischemic retinopathy; therefore, in an attempt to re-equilibrate their metabolic supply, they produce exaggerated amounts (far above normal developmental levels) of oxygen-regulated angiogenic factors such as VEGF and Epo (reviewed in refs. $96,97,126)$. As a consequence, the ensuing regrowth becomes overstated, deregulated, and misguided toward the vitreous and lens. This profuse growth can culminate with the formation of a fibrous scar and contractile band that exert torsion and can ultimately sever the retina from the retinal pigment epithelium (i.e., it can cause retinal detachment).

Metabolite signaling. The role of a vascular network is to ensure the essential delivery of nutrients and oxygen. Therefore, it is imperative for a cell during hypoxic/ischemic episodes to respond to an energy imbalance and signal to reinstate vascular supply. Perhaps the most efficient manner in which this can occur is by harnessing the intermediates of its own energy metabolism. In this regard, a new paradigm of signaling via energy metabolites in response to compromised energy status has recently been proposed as an important contributor to both physiologic and pathologic vascularization in the retina $(83,127-129)$. The best-described examples of this evolutionarily preserved primitive system involve signaling by succinate and adenosine and are described below.

Succinate is a dicarboxylate generated as a metabolite of the Krebs cycle during cellular respiration, while adenosine is a purine nucleoside produced during ATP metabolism. Beyond their wellestablished roles in energy production, these molecules bind and activate $G$ protein-coupled receptors, implying additional physiological roles. Consistent with mediating compensatory angiogenesis, both intermediates are upregulated under hypoxic conditions. When oxygenation is adequate, the Krebs cycle produces energy, and hence ATP levels are high and adenosine is low. Conversely, in low-oxygen conditions, Krebs cycle intermediates, such as succinate, accumulate, owing to feedback inhibition of succinate (and $\alpha$-ketoglutarate) dehydrogenase by nonoxidized flavin and nicotinamide nucleotides and by ROS $(130,131)$. Consequently, ATP is low and adenosine is high. In turn, succinate and adenosine act as proangiogenic mediators to reinstate adequate blood supply and oxygen delivery $(83,127,128,132)$. The robust vascular response provoked by these metabolites is suggestive of a direct role in linking energy demand to capillary growth. Importantly, 


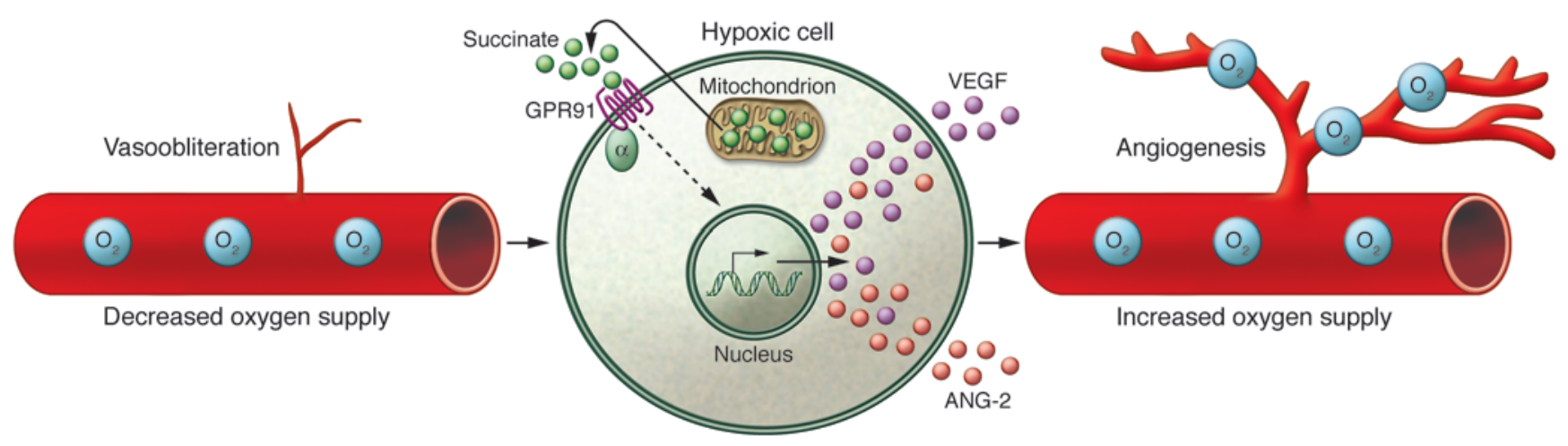

Figure 5

The proangiogenic effects of metabolite signaling in ROP. During hypoxia, as seen in ROP/OIR following hyperoxia-induced microvascular degeneration, succinate accumulates. Through its actions on its receptor, GPR91, which is present on retinal ganglion cells (RGCs), succinate induces production of a pleiotropy of proangiogenic factors, which trigger neovascular formation. This new vessel growth attempts to restore oxygen supply to the hypoxic retina; however, in ROP this compensatory vascular expansion is exaggerated and penetrates the vitreous. ANG-2, angiopoietin 2.

succinate signaling is thought to be a master regulator of both development and pathological retinal angiogenesis (83); this signaling pathway is operational before HIF stabilization and is thus an antecedent sensor of hypoxic stress.

The contribution of both succinate and adenosine to the proliferative phase of ROP has been established by inhibiting their cognate receptors in the OIR mouse model. Treatment with either siRNA or lentiviral vectors carrying shRNAs targeting the succinate receptor GPR91 effectively attenuates the proliferative phase of ROP in an OIR model (83). Similarly, selective antagonists of the $A_{2 B}$ adenosine receptor profoundly reduce preretinal neovascularization (on the retinal-vitreal interface) (Figure 1) (129). It is noteworthy that both succinate and adenosine derive their angiogenic potential from cells other than the endothelium; monocytes express adenosine receptors (133), while neurons (retinal ganglion cells) express both adenosine and succinate receptors $(83,134)$. Deficiency in monocytes or retinal ganglion cells (either by destruction or genetic ablation) interferes profoundly with retinal vascular development in mice $(83,135)$. The findings provide insight into a signaling paradigm in which cells in the vicinity of hypoxic zones provoke an angiogenic response to restore metabolic equilibrium, thus linking metabolism to vascular supply (Figure 5). Given the growing number of metabolites being identified as ligands for previously orphaned $G$ protein-coupled receptors, these findings open the door for exploration of a novel family of mediators of pathological neovascularization in ROP.

Lipid signaling and vasoproliferation. The heightened level of inflammation associated with ischemic retinopathies (136-138) suggests that blocking enzymes that directly contribute to the inflammatory state may be an interesting strategy to curb both the vasoobliteration and neovascularization phases of ROP. The response of a tissue to inflammatory stimuli is largely orchestrated by mediators such as lipids, nucleotides, and peptides. Inflammatory mediators can lead to cytotoxicity or cytoproliferation, depending on the agent, the concentration, and the condition. The role of cytotoxic phospholipids has been addressed above (see Oxygen-dependent factors: oxidative and nitrative stress and their downstream effects).

Among the most prominent mediators of inflammation are the eicosanoids derived from essential $\omega-3$ and $\omega-6$ long-chain PUFAs (LCPUFAs) (139); both $\omega-3$ and $\omega-6$ PUFAs are highly expressed in the retina. Simply put, the proinflammatory 2-series prostaglandins and leukotrienes are derived from the $\omega-6 \mathrm{AA}$. In contrast, the antiinflammatory neuroprotectins and $\mathrm{D}$-series resolvins originate from the $\omega-3$ DHA and the E-series resolvins and 3-series prostaglandins from eicosapentaenoic acid (EPA). There are two principal families of enzymes that convert LCPUFAs to biologically active entities: the COXs and the lipoxygenases. The molecular basis for the health benefits of $\omega-3$ PUFAs is thought to occur primarily through the direct integration of EPA and DHA at the sn 2 position of membrane phospholipids, which thus unseats $\omega-6$ PUFAs such

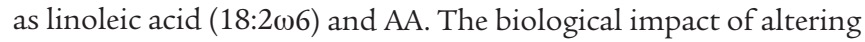
lipid intake is thought to occur primarily through modification of membrane microdomain composition and specific receptors.

A successful strategy to alter the inflammatory status of the retina stems directly from influencing dietary lipid intake. Studies using the mouse OIR model demonstrate that diets enriched in $\omega-3$ LCPUFAs (mimicking Japanese diets) effectively increase total retinal content of $\omega$-3 fatty acids and translate into decreased avascular zones and protection against neovascularization when compared with diets rich in $\omega-6$ LCPUFAs (mimicking Western diets) (136). This beneficial effect is in part explained by an augmented retinal content of the antiinflammatory neuroprotectins and resolvins derived from $\omega-3$ PUFAs, which suppress production of excessive cytotoxic concentrations of TNF- $\alpha$ from microglial cells.

Further evidence of the involvement of cytoprotective inflammatory lipid mediators in ROP comes from work on COX (138). In both patients with symptomatic diabetes and in a mouse OIR model, the inducible form of COX, COX-2, shows altered expression patterns when compared with that in healthy individuals and is localized primarily in the nerve fiber layer (adjacent the retinal vasculature) (140). It also has been shown that COX-2 participates in neovascularization via the generation of $\mathrm{PGE}_{2}$ and its activation of PGE receptor 3 (EP3) and to a lesser extent EP2 (140). Future studies will be required to address the relevance of the lipoxygenase pathways and their metabolites in ROP.

\section{Prevention and therapy of ROP}

Prevention. Preventive measures against ROP have so far been modestly successful, largely due to an incomplete understanding of pathogenesis and limited efficacy of therapeutic modalities. To 


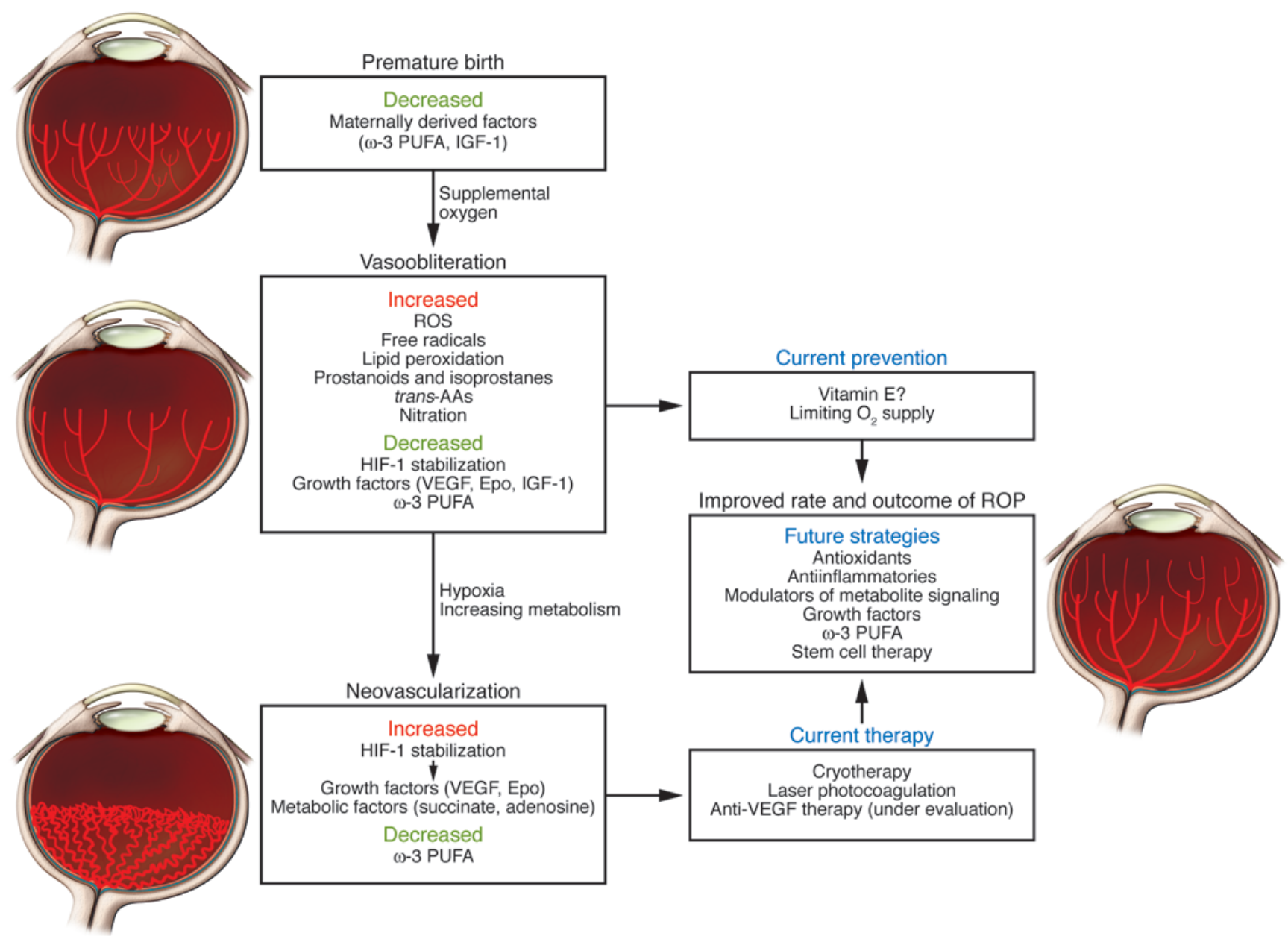

Figure 6

Summary illustration of the current concepts in ROP. When premature birth occurs, the retinal vasculature, which normally develops until birth, is immature. In addition, the premature infant is deficient in several maternally derived factors (such as $\omega-3$ PUFAs and IGF-1, which are transferred during the third trimester) that are essential for healthy blood vessel development, thus further compromising the prognosis. Moreover, the premature patient is mechanically ventilated to overcome pulmonary insufficiencies, and as a consequence, the supplemental oxygen given during mechanical ventilation contributes to retinal vascular obliteration due to oxidant stress and suppression of oxygen-regulated proangiogenic factors such as VEGF and Epo. Following the initial phase of vascular dropout, a second phase of compensatory and destructive neovascularization results and is driven by hypoxia-induced angiogenic factors. Current therapeutic interventions rely on invasive procedures such as laser photocoagulation, whereby affected areas of the retina are cauterized. A number of future treatments, including anti-VEGF therapy and the use of antioxidants, are currently being evaluated.

date, the most effective means to diminish the rates of ROP largely involve restricting tissue oxygenation by maintaining lower levels of hemoglobin saturation with oxygen in infants born prematurely $(17,18,100)$. Other preventive strategies rigorously studied include the early use of antioxidants, notably vitamin E. Vitamin E is a naturally occurring potent, free radical scavenger that decreases lipid peroxidation and helps maintain membrane integrity (141). Infants born prematurely have only $10 \%$ of adult levels of retinal vitamin $\mathrm{E}$ (51), which provides a rationale for using vitamin $\mathrm{E}$ in prevention of ROP. Four clinical trials involving premature infants ( $<1,500 \mathrm{~g}$ birth weight) demonstrated that vitamin E suppressed the development of severe ROP. However, subsequent trials could not reproduce earlier results (142-144), and hence the efficacy of vitamin E remains is at best modest (145).

Therapy. Current therapeutic approaches tackle late-appearing neovascularization. Laser photocoagulation (where an area of the retina affected by ROP is cauterized) has, for the last decade, been the mainstay of therapy in ROP (Figure 6). Laser photocoagulation was implemented in the clinic following recommendations made as a result of the cryotherapy trial for advancing forms of ROP at high risk of progressive intravitreal neovascularization (146). Early intervention in ROP has led to improved visual outcome (147), although undesired long-term outcome of laser therapy on visual acuity and fields cannot be disregarded (148).

A promising future strategy to counter ROP is to use anti-VEGF therapy. To date, 9 reports (including 6 case reports, 2 retrospective studies, and 1 prospective study) document results of therapy with a VEGF-specific neutralizing antibody (bevacizumab) in ROP, and these have been reviewed in ref. 149. Timing (stage/zone of ROP), dose (0.4-12.5 mg intravitreal), and frequency of administration of bevacizumab, as well as cotreatment with photocoagulation, varied tremendously among reports. Nonetheless, generally favorable 
outcome (controlled progressive neovascularization) was noted in 6 of the 9 small reports. However, this leaves a number of issues to be addressed in upcoming randomized trials, including: (a) adjunct photocoagulation therapy with anti-VEGF treatment; (b) impact on retinal ganglion cell integrity, since these neurons express the receptor for VEGF and VEGF can act as a cytoprotective factor for retinal ganglion cells; (c) timing of anti-VEGF therapy; (d) systemic effects of larger doses $(1.25 \mathrm{mg})$ of bevacizumab, notably on cerebral vasculature; (e) long-term impact on visual acuity and visual fields; (f) cost-benefit versus currently available treatment.

\section{Future perspectives}

One of the most destructive manifestations of ROP is preretinal neovascularization (Figure 1). Approaches to prevent vasoobliteration or accelerate normal vascular repair following initial microvascular degeneration would ideally curb the development of late-appearing harmful neovascularization (Figure 6). As we continue to decipher the underlying cellular mechanisms governing proliferative retinopathies such as ROP, fostering rapid normal retinal revascularization may open new therapeutic avenues. Insight into the complex cellular interdependent network of retinal neurons, microglia, astroglia, and vessels is being unraveled from the perspective of their respective energy requirements. The metabolic demands of these cell populations link them to vascular supply. In this context, numerous energy metabolites are now being identified as ligands for previously orphaned $G$ protein-coupled receptors. Harnessing components of cellular energy metabolism and metabolite signaling may help modulate normal

1. Gibson DL, Sheps SB, Schechter MT, Wiggins S, McCormick AQ. Retinopathy of prematurity: a new epidemic? Pediatrics. 1989;83(4):486-492.

2. Lee SK, et al. Variations in practice and outcomes in the Canadian NICU network: 1996-1997. Pediatrics. 2000;106(5):1070-1079.

3. Phelps DL. Retinopathy of prematurity. $N$ Engl J Med. 1992;326(16):1078-1080.

4. Dobson V, et al. Color vision measured with pseudoisochromatic plates at five-and-a-half years in eyes of children from the CRYO-ROP study. Invest Ophthalmol Vis Sci. 1996;37(12):2467-2474.

5. Hack M, Taylor HG, Klein N, Eiben R, Schatschneider C, Mercuri-Minich N. School-age outcomes in children with birth weights under $750 \mathrm{~g}$. N Engl JMed. 1994;331(12):753-759.

6. Kushner BJ. Strabismus and amblyopia associated with regressed retinopathy of prematurity. Arch Ophthalmol. 1982;100(2):256-261.

7. Ashton N. Oxygen and the growth and development of retinal vessels. In vivo and in vitro studies. The XX Francis I. Proctor Lecture. Am J Ophthalmol. 1966;62(3):412-435.

8. McLeodDS, Brownstein R, Lutty GA. Vaso-obliteration in the canine model of oxygen-induced retinopathy. Invest Ophthalmol Vis Sci. 1996;37(2):300-311.

9. Berkowitz BA, Penn JS. Abnormal panretinal response pattern to carbogen inhalation in experimental retinopathy of prematurity. Invest Ophthalmol Vis Sci. 1998;39(5):840-845.

10. Penn JS, Henry MM, Tolman BL. Exposure to alternating hypoxia and hyperoxia causes severe proliferative retinopathy in the newborn rat. Pediatr Res. 1994;36(6):724-731.

11. Roth AM. Retinal vascular development in premature infants. Am J Ophthalmol. 1977;84(5):636-640.

12. Smith LE, et al. Oxygen-induced retinopathy in the mouse. Invest Ophthalmol Vis Sci. 1994;35(1):101-111.

13. Penn JS, Tolman BL, Lowery LA. Variable oxygen exposure causes preretinal neovascularization in the newborn rat. Invest Ophthalmol Vis Sci.

and pathologic neovascularization (83). Along similar lines of thought, a more profound understanding of the complex interplay of inflammatory mediators is needed. Novel vascular repair strategies may also emerge from advances in regenerative medicine using stem cells, including the findings that hematopoietic stem cells home into areas of vascular damage and that engineered stem cells injected into the eye hasten vascular repair (150). Future safe and nondestructive therapeutic strategies combined with preventive approaches need to be tailored to the unique developmental requirements of the premature infant.

\section{Acknowledgments}

P. Sapieha is supported by grants from the Canadian Institutes of Health Research (CIHR) and the Charles A. King Trust Award and Canadian National Institute for the Blind. J.-S. Joyal is a recipient of an award from the Canadian Child Health Clinician Scientist Program, a CIHR training initiative. J.C. Rivera is supported by the Heart and Stroke Foundation of Canada (HSCF) and the Canadian Stroke Network (CSN). S. Chemtob holds a Canada Research Chair (perinatology) and the Leopoldine Wolfe Chair in translational research in age-related macular degeneration and is supported by grants from the CIHR.

Address correspondence to: Sylvain Chemtob, Departments of Pediatrics, Ophthalmology and Pharmacology, Research Center, Sainte-Justine Hospital, Montreal, Quebec, Canada, H3T 1C5. Phone: 514.345.4931, ext. 2978; Fax: 514.345.4801; E-mail: sylvain. chemtob@umontreal.ca.

1993;34(3):576-585.

14. Stahl A, et al. Computer-aided quantification of retinal neovascularization. Angiogenesis. 2009;12(3):297-301.

15. Kinsey VE. Cooperative study of retrolental fibroplasia and the use of oxygen. AMA Arch Ophthalmol. 1956;56(4):481-453.

16. Kinsey VE, et al. $\mathrm{PaO} 2$ levels and retrolental fibroplasia: a report of the cooperative study. Pediatrics. 1977;60(5):655-668.

17. Holmes JM, Zhang S, Leske DA, Lanier WL. Carbon dioxide-induced retinopathy in the neonatal rat. Curr Eye Res. 1998;17(6):608-616.

18. Ajayi OA, Raval D, Lucheese N, Pildes RS. Ophthalmological morbidity in very-low-birthweight infants with bronchopulmonary dysplasia. J Natl Med Assoc. 1997;89(10):679-683.

19. Holmes JM, Leske DA, Zhang S. The effect of raised inspired carbon dioxide on normal retinal vascular development in the neonatal rat. Curr Eye Res. 1997;16(1):78-81.

20. Ehinger B, Falck B. Concomitant adrenergic and parasympathetic fibres in the rat iris. Acta Physiol Scand. 1966;67(2):201-207.

21. Hoste AM, Boels PJ, Andries LJ, Brutsaert DL, De Laey JJ. Effects of beta-antagonists on contraction of bovine retinal microarteries in vitro. Invest Ophthalmol Vis Sci. 1990;31(7):1231-1237.

22. Laties AM. Central retinal artery innervation. Absence of adrenergic innervation to the intraocular branches. Arch Ophthalmol. 1967;77(3):405-409.

23. Guyton AC. The relationship of cardiac output and arterial pressure control. Circulation. 1981;64(6):1079-1088.

24. Alm A, Bill A. The oxygen supply to the retina. II. Effects of high intraocular pressure and of increased arterial carbon dioxide tension on uveal and retinal blood flow in cats. A study with radioactively labelled microspheres including flow determinations in brain and some other tissues. Acta Physiol Scand. 1972;84(3):306-319.
25. Chemtob S, Beharry K, Rex J, Chatterjee T, Varma DR, Aranda JV. Ibuprofen enhances retinal and choroidal blood flow autoregulation in newborn piglets. Invest Ophthalmol Vis Sci. 1991; 32(6):1799-1807.

26. Hardy P, Nuyt AM, Abran D, St-Louis J, Varma DR, Chemtob S. Nitric oxide in retinal and choroidal blood flow autoregulation in newborn pigs: interactions with prostaglandins. Pediatr Res. 1996;39(3):487-493.

27. Hardy P, Abran D, Li DY, Fernandez H, Varma DR, Chemtob S. Free radicals in retinal and choroidal blood flow autoregulation in the piglet: interaction with prostaglandins. Invest Ophthalmol Vis Sci. 1994;35(2):580-591.

28. Riva CE, Grunwald JE, Petrig BL. Autoregulation of human retinal blood flow. An investigation with laser Doppler velocimetry. Invest Ophthalmol Vis Sci. 1986;27(12):1706-1712.

29. Tachibana H, Gotoh F, Ishikawa Y. Retinal vascular autoregulation in normal subjects. Stroke. 1982;13(2):149-155.

30. Milligan DW. Failure of autoregulation and intraventricular haemorrhage in preterm infants. Lancet. 1980;1(8174):896-898.

31. Pryds O, Greisen G, Lou H, Friis-Hansen B. Heterogeneity of cerebral vasoreactivity in preterm infants supported by mechanical ventilation. $J$ Pediatr. 1989;115(4):638-645.

32. Perlman JM, Goodman S, Kreusser KL, Volpe JJ. Reduction in intraventricular hemorrhage by elimination of fluctuating cerebral blood-flow velocity in preterm infants with respiratory distress syndrome. N Engl J Med. 1985;312(21):1353-1357.

33. Yu DY, Cringle SJ, Alder VA, Su EN, Yu PK. Intraretinal oxygen distribution and choroidal regulation in the avascular retina of guinea pigs. Am J Physiol. 1996;270(3 pt 2):H965-H973.

34. Kiel JW, van Heuven WA. Ocular perfusion pressure and choroidal blood flow in the rabbit. Invest Ophthalmol Vis Sci. 1995;36(3):579-585. 
35. Hardy P, Peri KG, Lahaie I, Varma DR, Chemtob $\mathrm{S}$. Increased nitric oxide synthesis and action preclude choroidal vasoconstriction to hyperoxia in newborn pigs. Circ Res. 1996;79(3):504-511.

36. Hardy P, et al. Major role for neuronal NO synthase in curtailing choroidal blood flow autoregulation in newborn pig. J Appl Physiol. 2001; 91(4):1655-1662.

37. Kiel JW, Shepherd AP. Autoregulation of choroidal blood flow in the rabbit. Invest Ophthalmol Vis Sci. 1992;33(8):2399-2410.

38. Shvedova AA, Alekseeva OM, IYa K, Muranov KO, YuP K, Kagan VE. Damage of photoreceptor membrane lipids and proteins induced by photosensitized generation of singlet oxygen. Curr Eye Res. 1982;2(10):683-689.

39. Abran D, Varma DR, Chemtob S. Increased thromboxane-mediated contractions of retinal vessels of newborn pigs to peroxides. Am J Physiol. 1995;268(2 pt 2):H628-H632.

40. Kulkarni P, Cai J, Hurst HE. Lipids and nitric oxide in porcine retinal and choroidal blood vessels. J Ocul Pharmacol Ther. 2002;18(3):265-275.

41. Kuriyama H, Waki M, Nakagawa M, Tsuda M. Involvement of oxygen free radicals in experimental retinal ischemia and the selective vulnerability of retinal damage. Ophthalmic Res. 2001;33(4):196-202.

42. Siu AW, To CH. Nitric oxide and hydroxyl radicalinduced retinal lipid peroxidation in vitro. Clin Exp Optom. 2002;85(6):378-382.

43. Checchin D, et al. PGE(2)-mediated eNOS induction in prolonged hypercapnia. Invest Ophthalmol Vis Sci. 2002;43(5):1558-1566.

44. Giusto NM, Pasquaré SJ, Salvador GA, Castagnet PI Roque ME, Ilincheta de Boschero MG. Lipid metabolism in vertebrate retinal rod outer segments. Prog Lipid Res. 2000;39(4):315-391.

45. Guzy RD, Schumacker PT. Oxygen sensing by mitochondria at complex III: the paradox of increased reactive oxygen species during hypoxia. Exp Physiol. 2006;91(5):807-819.

46. Shvedova AA, Alekseeva OM, Kuliev I, Muranov KO, Kozlov Yu P, Kagan VE. Damage of photoreceptor membrane lipids and proteins induced by photosensitized generation of singlet oxygen. Curr Eye Res. 1982;2(10):683-689.

47. Daemen FJ. Vertebrate rod outer segment membranes. Biochim Biophys Acta. 1973;300(3):255-288.

48. Delmelle M. Possible implication of photooxidation reactions in retinal photo-damage. Photochem Photobiol. 1979;29(4):713-716.

49. Stamler JS, Singel DJ, Loscalzo J. Biochemistry of nitric oxide and its redox-activated forms. Science. 1992;258(5090):1898-1902.

50. Moncada S, Higgs A, Furchgott R. International union of pharmacology nomenclature in nitric oxide research. Pharmacol Rev. 1997;49(2):137-142.

51. Nielsen JC, Naash MI, Anderson RE. The regional distribution of vitamins $\mathrm{E}$ and $\mathrm{C}$ in mature and premature human retinas. Invest Ophthalmol Vis Sci. 1988;29(1):22-26.

52. Flynn JT, et al. A cohort study of transcutaneous oxygen tension and the incidence and severity of retinopathy of prematurity. $N \mathrm{Engl} \mathrm{J} \mathrm{Med}$. 1992;326(16):1050-1054.

53. Chemtob S, et al. Peroxide-cyclooxygenase interactions in postasphyxial changes in retinal and choroidal hemodynamics. J Appl Physiol. 1995;78(6):2039-2046.

54. Squadrito GL, Pryor WA. Oxidative chemistry of nitric oxide: the roles of superoxide, peroxynitrite, and carbon dioxide. Free Radic Biol Med. 1998; 25(4-5):392-403.

55. Kröncke K-D. Mechanisms and biological consequences of nitrosative stress. Biol Chem. 2003;384(10-11): 1341 .

56. Beauchamp MH, et al. Redox-dependent effects of nitric oxide on microvascular integrity in oxy- gen-induced retinopathy. Free Radic Biol Med. 2004;37(11):1885-1894.

57. Gu X, El-Remessy AB, Brooks SE, Al-Shabrawey M, Tsai N-T, Caldwell RB. Hyperoxia induces retinal vascular endothelial cell apoptosis through formation of peroxynitrite. Am J Physiol Cell Physiol. 2003;285(3):C546-C554.

58 . Brooks SE, et al. Reduced severity of oxygeninduced retinopathy in eNOS-deficient mice. Invest Ophthalmol Vis Sci. 2001;42(1):222-228.

59. Sennlaub F, Courtois Y, Goureau O. Inducible nitric oxide synthase mediates the change from retinal to vitreal neovascularization in ischemic retinopathy. J Clin Invest. 2001;107(6):717-725.

60. Anderson SM, Krinsky NI. Protective action of carotenoid pigments against photodynamic damage to liposomes. Photochem Photobiol. 1973;18(5):403-408.

61. Arstila AU, Smith MA, Trump BF. Microsomal lipid peroxidation: morphological characterization. Science. 1972;175(21):530-533.

62. Kondo T, Kinouchi H, Kawase M, Yoshimoto T. Differential response in the release of hydrogen peroxide between astroglial cells and endothelial cells following hypoxia/reoxygenation. Neurosci Lett. 1996;215(2):103-106.

63. D'Amore PA, Sweet E. Effects of hyperoxia on microvascular cells in vitro. In Vitro Cell Dev Biol. 1987;23(2):123-128.

64. Halks-Miller M, Henderson M, Eng LF. Alpha tocopherol decreases lipid peroxidation, neuronal necrosis, and reactive gliosis in reaggregate cultures of fetal rat brain. J Neuropathol Exp Neurol. 1986;45(4):471-484.

65. Hubel CA, Davidge ST, McLaughlin MK. Lipid hydroperoxides potentiate mesenteric artery vasoconstrictor responses. Free Radic Biol Med. 1993 ; 14(4):397-407.

66. Hemler ME, Cook HW, Lands WE. Prostaglandin biosynthesis can be triggered by lipid peroxides. Arch Biochem Biophys. 1979;193(2):340-345.

67. Beauchamp $\mathrm{MH}$, et al. Role of thromboxane in retinal microvascular degeneration in oxygen-induced retinopathy. J Appl Physiol. 2001;90(6):2279-2288.

68. Hou X, et al. Augmented vasoconstriction and thromboxane formation by $15-\mathrm{F}(2 \mathrm{t})$-isoprostane (8-iso-prostaglandin $\mathrm{F}(2 \mathrm{alpha})$ ) in immature pig periventricular brain microvessels. Stroke. 2000;31(2):516-524.

69. Morrow JD, et al. Free radical-induced generation of isoprostanes in vivo. Evidence for the formation of D-ring and E-ring isoprostanes. J Biol Chem. 1994;269(6):4317-4326.

70. Brault $S$, et al. Selective neuromicrovascular endothelial cell death by 8-Iso-prostaglandin F2alpha: possible role in ischemic brain injury. Stroke. 2003;34(3):776-782.

71. Balazy M, Chemtob S. Trans-arachidonic acids: new mediators of nitro-oxidative stress. Pharmacol Ther. 2008;119(3):275-290.

72. Jiang H, Kruger N, Lahiri DR, Wang D, Vatèle JM, Balazy M. Nitrogen dioxide induces cis-trans-isomerization of arachidonic acid within cellular phospholipids. Detection of trans-arachidonic acids in vivo. J Biol Chem. 1999;274(23):16235-16241.

73. Balazy M. Trans-arachidonic acids: new mediators of inflammation. J Physiol Pharmacol. 2000; 51(4 pt 1):597-607.

74. Zghibeh CM, Raj Gopal V, Poff CD, Falck JR, Balazy M. Determination of trans-arachidonic acid isomers in human blood plasma. Anal Biochem. 2004;332(1):137-144

75. Kermorvant-Duchemin E, et al. Trans-arachidonic acids generated during nitrative stress induce a thrombospondin-1-dependent microvascular degeneration. Nat Med. 2005;11(12):1339-1345.

76. Liu L, et al. Essential roles of S-nitrosothiols in vascular homeostasis and endotoxic shock. Cell.
2004;116(4):617-628

77. Llorens S, Nava E. Cardiovascular diseases and the nitric oxide pathway. Curr Vasc Pharmacol. 2003; 1(3):335-346.

78. Snyder F. Platelet-activating factor and related acetylated lipids as potent biologically active cellular mediators. Am J Physiol. 1990;259(5 pt 1):C697-C708.

79. Beauchamp MH, et al. Platelet-activating factor in vasoobliteration of oxygen-induced retinopathy. Invest Ophthalmol Vis Sci. 2002;43(10):3327-3337.

80. Hou X, et al. Increased platelet-activating factorinduced periventricular brain microvascular constriction associated with immaturity. Am J Physiol Regul Integr Comp Physiol. 2003;284(4):R928-R935.

81. Xie Y, Meier KE. Lysophospholipase D and its role in LPA production. Cell Signal. 2004;16(9):975-981.

82. Brault $S$, et al. Lysophosphatidic acid induces endothelial cell death by modulating the redox environment. Am J Physiol Regul Integr Comp Physiol. 2007;292(3):R1174-R1183.

83. Sapieha P, et al. The succinate receptor GPR91 in neurons has a major role in retinal angiogenesis. Nat Med. 2008;14(10):1067-1076.

84. Bruick RK. Expression of the gene encoding the proapoptotic Nip3 protein is induced by hypoxia. Proc Natl Acad Sci U S A. 2000;97(16):9082-9087.

85. Wenger RH, Stiehl DP, Camenisch G. Integration of oxygen signaling at the consensus HRE. Sci STKE. 2005;2005(306):re12.

86. Flynn JT, et al. A cohort study of transcutaneous oxygen tension and the incidence and severity of retinopathy of prematurity. $N$ Engl J Med. 1992;326(16):1050-1054.

87. Wang GL, Jiang BH, Rue EA, Semenza GL. Hypoxia-inducible factor 1 is a basic-helix-loop-helix-PAS heterodimer regulated by cellular $\mathrm{O} 2$ tension. Proc Natl Acad Sci U S A. 1995;92(12):5510-5514.

88. Yu AY, Frid MG, Shimoda LA, Wiener CM, Stenmark K, Semenza GL. Temporal, spatial, and oxygen-regulated expression of hypoxia-inducible factor- 1 in the lung. Am J Physiol. 1998;275(4 pt 1):L818-L826.

89. Chapman-Smith A, Whitelaw ML. Novel DNA binding by a basic helix-loop-helix protein. The role of the dioxin receptor PAS domain. J Biol Chem. 2006;281(18):12535-12545.

90. Bruick RK. Oxygen sensing in the hypoxic response pathway: regulation of the hypoxia-inducible transcription factor. Genes Dev. 2003;17(21):2614-2623.

91. Paul SA, Simons JW, Mabjeesh NJ. HIF at the crossroads between ischemia and carcinogenesis. $J$ Cell Physiol. 2004;200(1):20-30.

92. Semenza GL. Targeting HIF-1 for cancer therapy. Nat Rev Cancer. 2003;3(10):721-732.

93. Liu Y, Cox SR, Morita T, Kourembanas S. Hypoxia regulates vascular endothelial growth factor gene expression in endothelial cells. Identification of a 5' enhancer. Circ Res. 1995;77(3):638-643.

94. Wang GL, Semenza GL. General involvement of hypoxia-inducible factor 1 in transcriptional response to hypoxia. Proc Natl Acad Sci U S A. 1993;90(9):4304-4308.

95. Alon T, Hemo I, Itin A, Pe'er J, Stone J, Keshet E. Vascular endothelial growth factor acts as a survival factor for newly formed retinal vessels and has implications for retinopathy of prematurity. Nat Med. 1995;1(10):1024-1028.

96. Kermorvant-Duchemin E, et al. Understanding ischemic retinopathies: emerging concepts from oxygen-induced retinopathy. Doc Ophthalmol. 2010;120(1):51-60.

97. Smith LE. Through the eyes of a child: understanding retinopathy through ROP the Friedenwald lecture. Invest Ophthalmol Vis Sci. 2008;49(12):5177-5182.

98. Dorrell MI, Aguilar E, Friedlander M. Retinal vascular development is mediated by endothelial filopodia, a preexisting astrocytic template and specific R-cadherin adhesion. Invest Ophthalmol Vis Sci. 2002;43(11):3500-3510. 
99. Chen J, Connor KM, Aderman CM, Smith LE. Erythropoietin deficiency decreases vascular stability in mice. J Clin Invest. 2008;118(2):526-533.

100. Holmes JM, Zhang S, Leske DA, Lanier WL. The effect of carbon dioxide on oxygen-induced retinopathy in the neonatal rat. Curr Eye Res. 1997; 16(7):725-732.

101.Simons BD, Flynn JT. Retinopathy of prematurity and associated factors. Int Ophthalmol Clin. 1999;39(2):29-48.

102. Hellstrom A, et al. Low IGF-I suppresses VEGFsurvival signaling in retinal endothelial cells: direct correlation with clinical retinopathy of prematurity. Proc Natl Acad Sci U S A. 2001;98(10):5804-5808

103. Lofqvist $C$, et al. IGFBP3 suppresses retinopathy through suppression of oxygen-induced vessel loss and promotion of vascular regrowth. Proc Natl Acad Sci US A. 2007;104(25):10589-10594.

104.Smith LE, et al. Essential role of growth hormone in ischemia-induced retinal neovascularization. Science. 1997;276(5319):1706-1709.

105.Smith LE, et al. Regulation of vascular endothelial growth factor-dependent retinal neovascularization by insulin-like growth factor-1 receptor. Nat Med. 1999;5(12):1390-1395

106.Lofquist C, et al. Postnatal head growth deficit among premature infants parallels retinopathy of prematurity and insulin-like growth factor-1 deficit. Pediatrics. 2006;117(6):1930-1938.

107. Firth SM, Baxter RC. Cellular actions of the insulin-like growth factor binding proteins. Endocr Rev. 2002;23(6):824-854.

108. Chen J, Smith LEH. Retinopathy of prematurity. Angiogenesis. 2007;10(2):133-140.

109.Lofqvist C, et al. Longitudinal postnatal weight and insulin-like growth factor I measurements in the prediction of retinopathy of prematurity. Arch Ophthalmol. 2006;124(12):1711-1718.

110. Hellstrom A, et al. Early weight gain predicts retinopathy in preterm infants: new, simple, efficient approach to screening. Pediatrics. 2009;123(4):e638-e645.

111.Dorrell MI, Friedlander M. Mechanisms of endothelial cell guidance and vascular patterning in the developing mouse retina. Prog Retin Eye Res. 2006;25(3):277-295.

112. Fruttiger $\mathrm{M}$, et al. PDGF mediates a neuron-astrocyte interaction in the developing retina. Neuron. 1996;17(6):1117-1131.

113. Stone J, et al. Development of retinal vasculature is mediated by hypoxia-induced vascular endothelial growth factor (VEGF) expression by neuroglia. J Neurosci. 1995;15(7 pt 1):4738-4747.

114.Fruttiger M. Development of the mouse retinal vasculature: angiogenesis versus vasculogenesis. Invest Ophthalmol Vis Sci. 2002;43(2):522-527.

115. Gariano RF. Cellular mechanisms in retinal vascular development. Prog Retin Eye Res. 2003;22(3):295-306.

116.Dorrell M, Friedlander M. Mechanisms of endothelial cell guidance and vascular patterning in the developing mouse retina. Prog Retin Eye Res. 2006;25(3):277-295.

117. Provis JM, Leech J, Diaz CM, Penfold PL, Stone J,
Keshet E. Development of the human retinal vasculature: cellular relations and VEGF expression. Exp Eye Res. 1997;65(4):555-568.

118. Ramsauer M, D'Amore PA. Getting Tie(2)d up in angiogenesis. J Clin Invest. 2002;110(11):1615-1617.

119. Gerhardt H, et al. VEGF guides angiogenic sprouting utilizing endothelial tip cell filopodia. $J$ Cell Biol. 2003;161(6):1163-1177.

120.Adams RH, et al. Roles of ephrinB ligands and EphB receptors in cardiovascular development: demarcation of arterial/venous domains, vascular morphogenesis, and sprouting angiogenesis. Genes Dev. 1999;13(3):295-306.

121. Klagsbrun M, Eichmann A. A role for axon guidance receptors and ligands in blood vessel development and tumor angiogenesis. Cytokine Growth Factor Rev. 2005;16(4-5):535-548.

122. Wilson BD, et al. Netrins promote developmental and therapeutic angiogenesis. Science. 2006;313(5787):640-644.

123.Dejana E, Tournier-Lasserve E, Weinstein BM. The control of vascular integrity by endothelial cell junctions: molecular basis and pathological implications. Dev Cell. 2009;16(2):209-221.

124. Ishida S, et al. Leukocytes mediate retinal vascular remodeling during development and vaso-obliteration in disease. Nat Med. 2003;9(6):781-788.

125. Das A, McGuire PG. Retinal and choroidal angiogenesis: pathophysiology and strategies for inhibition. Prog Retin Eye Res. 2003;22(6):721-748.

126.Lutty GA, et al. Proceedings of the third international symposium on retinopathy of prematurity: an update on ROP from the lab to the nursery (November 2003, Anaheim, California, USA). Mol Vis. 2006;12:532-580.

127. Grant MB, Davis MI, Caballero S, Feoktistov I, Biag gioni I, Belardinelli L. Proliferation, migration, and ERK activation in human retinal endothelial cells through $\mathrm{A}(2 \mathrm{~B})$ adenosine receptor stimulation. Invest Ophthalmol Vis Sci. 2001;42(9):2068-2073.

128. Grant MB, et al. Adenosine receptor activation induces vascular endothelial growth factor in human retinal endothelial cells. Circ Res. 1999;85(8):699-706

129. Mino RP, et al. Adenosine receptor antagonists and retinal neovascularization in vivo. Invest Ophthalmol Vis Sci. 2001;42(13):3320-3324.

130.Gutman M, Bonomi F, Pagani S, Cerletti P, Kroneck P. Modulation of the flavin redox potential as mode of regulation of succinate dehydrogenase activity. Biochim Biophys Acta. 1980;591(2):400-408

131. Meixner-Monori B, Kubicek CP, Habison A, Kubicek-Pranz EM, Rohr M. Presence and regulation of the alpha-ketoglutarate dehydrogenase multienzyme complex in the filamentous fungus Aspergillus niger. J Bacteriol. 1985;161(1):265-271.

132. Cronstein BN. Adenosine receptors and wound healing. ScientificWorldJournal. 2004;4:1-8.

133. Clark AN, et al. A1 adenosine receptor activation promotes angiogenesis and release of VEGF from monocytes. Circ Res. 2007;101(11):1130-1138.

134. Kvanta A, Seregard S, Sejersen S, Kull B, Fredholm $\mathrm{BB}$. Localization of adenosine receptor messenger
RNAs in the rat eye. Exp Eye Res. 1997;65(5):595-602. 135. Checchin D, Sennlaub F, Levavasseur E, Leduc M, Chemtob S. Potential role of microglia in retinal blood vessel formation. Invest Ophthalmol Vis Sci. 2006;47(8):3595-3602.

136. Connor KM, et al. Increased dietary intake of omega-3-polyunsaturated fatty acids reduces pathological retinal angiogenesis. Nat Med. 2007;13(7):868-873.

137. Kern TS. Contributions of inflammatory processes to the development of the early stages of diabetic retinopathy. Exp Diabetes Res. 2007;2007:95103.

138.SanGiovanni JP, Chew EY. The role of omega-3 long-chain polyunsaturated fatty acids in health and disease of the retina. Prog Retin Eye Res. 2005;24(1):87-138

139. Gronert K. Lipid autacoids in inflammation and injury responses: a matter of privilege. Mol Interv. 2008;8(1):28-35.

140.Sennlaub F, et al. Cyclooxygenase- 2 in human and experimental ischemic proliferative retinopathy. Circulation. 2003;108(2):198-204.

141.Engin KN. Alpha-tocopherol: looking beyond an antioxidant. Mol Vis. 2009;15:855-860.

142. Finer NN, Schindler RF, Grant G, Hill GB, Peters K. Effect of intramuscular vitamin $\mathrm{E}$ on frequency and severity of retrolental fibroplasia. A controlled trial. Lancet. 1982;1(8281):1087-1091.

143.Schaffer DB, Johnson L, Quinn GE, Weston M, Bowen FW Jr. Vitamin E and retinopathy of prematurity. Follow-up at one year. Ophthalmology. 1985;92(8):1005-1011.

144.Phelps DL, Rosenbaum AL, Isenberg SJ, Leake RD, Dorey FJ. Tocopherol efficacy and safety for preventing retinopathy of prematurity: a randomized, controlled, double-masked trial. Pediatrics. 1987;79(4):489-500.

145. Raju TN, Langenberg P, Bhutani V, Quinn GE. Vitamin $E$ prophylaxis to reduce retinopathy of prematurity: a reappraisal of published trials. J Pediatr. 1997;131(6):844-850.

146. Cryotherapy for Retinopathy of Prematurity Cooperative Group. Multicenter trial of cryotherapy for retinopathy of prematurity: preliminary results. Pediatrics. 1988;81(5):697-706.

147. Early Treatment For Retinopathy Of Prematurity Cooperative G. Revised indications for the treatment of retinopathy of prematurity: results of the early treatment for retinopathy of prematurity randomized trial. Arch Ophthalmol. 2003;121(12):1684-1694.

148. McLoone E, O'Keefe M, McLoone S, Lanigan B. Long term functional and structural outcomes of laser therapy for retinopathy of prematurity. $\mathrm{Br} \mathrm{J}$ Ophthalmol. 2006;90(6):754-759.

149.Micieli JA, Surkont M, Smith AF. A systematic analysis of the off-label use of bevacizumab for severe retinopathy of prematurity. Am J Ophthalmol. 2009;148(4):536-543 e532.

150. Otani A, Kinder K, Ewalt K, Otero FJ, Schimmel P, Friedlander M. Bone marrow-derived stem cells target retinal astrocytes and can promote or inhibit retinal angiogenesis. Nat Med. 2002;8(9):1004-1010. 